\title{
Deep-sea mining - a threat to the abyssal realm
}

\section{MATTHIAS HAECKEL}

\section{GEOMAR Helmholtz Centre for Ocean Research Kiel}

Presenting Author: mhaeckel@geomar.de

Exploitation of metal ores (polymetallic nodules, massive sulphides, and cobalt-rich crusts) from the deep seabed has been under discussion repeatedly since the 1970s. The recent engagement of various states and companies to develop this industry has been sparked by the projected future demands of metals for our transition to a low-carbon energy system and our increasing consumption of high-tech products in conjunction with global population growth. While extracting metals from deep-sea ores may contribute to the desired overall reduction of our $\mathrm{CO}_{2}$ emissions, it will certainly introduce a new threat to our oceans.

Abyssal ecosystems show unrivalled high biodiversity in combination with high spatial and temporal variability of faunal populations and environmental variables. The recent research of the European MiningImpact project on potential impacts from future deep-sea mining operations indicates that these will be severe and last for centuries to millennia. Currently designed mining technology will not only remove the metal ore, which forms the habitat for rich and specific benthic fauna, but the entire biologically active surface layer of the seafloor, which is at the basis of the abyssal food web. In addition, suspended particle plumes will blanket also the benthic ecosystem outside the mined areas. Larger-scale consequences are still uncertain because of largely unknown species connectivity and limited understanding of ecosystem structure and functions.

At the anticipated scale of damage of several hundreds of square square-kilometers per year for each nodule mining operation careful and adaptive spatial planning of mining operations on regional and even global scale is required. Conservation areas must be set aside that closely match ecosystem characteristics in mined areas, ecological indicators and threshold values for harmful effects must be defined. However, before we as society decide to engage in this destructive activity, threats, costs and benefits of all options, including technological and social innovations, need to be valued against each other in an open and transparent dialogue. 